\title{
Correction to: First-Principles Calculation of the Air-Water Second Virial Coefficient
}

\author{
A. H. Harvey ${ }^{1}$ D . P. H. Huang ${ }^{2}$
}

Published online: 12 October 2020

(c) Springer Science+Business Media, LLC, part of Springer Nature 2020

\section{Correction to: International Journal of Thermophysics 28:556 (2007) https://doi.org/10.1007/s10765-007-0197-8}

In the original article [1], an incorrect expression was written for the calculation of the expanded uncertainty of $B_{\mathrm{aw}}, U\left(B_{\mathrm{aw}}\right)$, from the uncertainties of the individual components. Equation (4) should be written as.

$$
U\left(B_{\mathrm{aw}}\right)=\left(\sum_{i=\mathrm{N}_{2}, \mathrm{O}_{2}, \mathrm{Ar}}\left[x_{i} U\left(B_{i \mathrm{w}}\right)\right]^{2}\right)^{0.5} .
$$

The uncertainty values reported in the paper were calculated with the correct expression.

We thank Robert Hellmann for noticing this error during the course of his work on Ref.[2], which to a large extent supersedes Ref.[1].

\section{References}

1. A.H. Harvey, P.H. Huang, First-principles calculation of the air-water second virial coefficient. Int. J. Thermophys. 28, 556 (2007). https://doi.org/10.1007/s10765-007-0197-8

2. R. Hellmann, Reference values for the cross second virial coefficients and dilute gas binary diffusion coefficients of the systems $\left(\mathrm{H}_{2} \mathrm{O}+\mathrm{O}_{2}\right)$ and $\left(\mathrm{H}_{2} \mathrm{O}+\right.$ Air) from first principles. J. Chem. Eng. Data 65, 4130 (2020). https://doi.org/10.1021/acs.jced.0c00465

The original article can be found online at https://doi.org/10.1007/s10765-007-0197-8.

A. H. Harvey

allan.harvey@nist.gov

1 Applied Chemicals and Materials Division, National Institute of Standards and Technology, 325 Broadway, Boulder, CO 80305, USA

2 National Institute of Standards and Technology, 100 Bureau Drive, Gaithersburg, MD 20899, USA 